\title{
CONTEMPORARY LINGUISTIC THEORIES OF HUMOUR
}

\author{
Arvo Krikmann
}

\begin{abstract}
The paper will discuss the following subtopics: Arthur Koestler's bisociation theory of humour and its reception; Victor Raskin's script-based theory of jokes (SSTH) in his "Semantic Mechanisms of Humor; the General Theory of Verbal Humor (GTVH) by Victor Raskin and Salvatore Attardo and the attempt of testing GTVH by Willibald Ruch; Salvatore Attardo's Linear Theory of Humor (IDM); The analysis of puns by Attardo; Humour and pragmatic maxims (Raskin, Attardo, etc.); Attardo's Setup-Incongruity-Resolution -model (SIR); The further taxonomy of "logical mechanisms" (LM) of jokes by Attardo, Hempelmann, and Di Maio; the "Anti-Festschrift" for Victor Raskin.

Keywords: Arthur Koestler; Victor Raskin; Salvatore Attardo; humour theories; jokes; incongruity; script opposition; logical mechanisms; puns; pragmatic maxims.
\end{abstract}

\section{ON THE TYPES OF HUMOUR THEORIES}

As is widely known, theories of humour are traditionally divided in three branches:

(1) Theories of incongruity, or inconsistency, or contradiction, or bisociation. Incongruity theories are essentially cognitive, i.e. they are based on some objective characteristics of a humorous text or other act (situation, event, picture, etc.). It is assumed that every such act involves two different planes of content $\sim$ lines of thought, in newer works the planes are called frames of reference, isotopies, schemas, scripts, etc. These two are mutually incompatible, but also include a certain common part which makes the shift from one to another possible. The recipient begins to process textual or other information reducing it to the most accessible salient "preprimed" script, and proceeds until the interpretation bounces over a semantic obstacle and fails. Then some instantaneous cognitive work will be done to overcome the contradiction and another interpretation that has so far remained hidden can be found. The renewal of understanding is attended by the emotion of surprise and satisfaction, causing the reaction of laughter.

(2) Theories of superiority, or disparagement, or criticism, or hostility that accentuate the (negative) attitude of the producer and/or user of humour towards its target and the often alleged aggressive character of laughter. That is, humour is said to be pointed against some person or group, typically on political, ethnic or gender grounds. 
(3) Theories of release, or relief, or relaxation, also known as psychoanalytic, Sigmund Freud being the most outstanding representative of them. This class of theories is focused mainly on the recipient of humour, or more specifically, on the psychological effects humour allegedly brings about in the recipient. Freud considers humour as one of the so-called substitution mechanisms which enable to convert one's socially tabooed aggressive impulses to acceptable ones and thus avoid wasting additional mental energy to suppress them.

Most of the humour theories ever proposed are actually mixed theories, and many contemporary researchers believe that humour in its totality is too huge and multiform a phenomenon to be incorporated into a single integrated theory.

'Linguistic theories' is a conditional name for the theories I aim to introduce here. All of them belong to, or are descendants of, or congenial with the incongruity theories just mentioned, though some authors of them prefer to deny it. Here I will briefly touch upon only three most prominent figures in the field - Arthur Koestler, Victor Raskin and Salvatore Attardo.

\section{ARTHUR KOESTLER AND THE ACT OF CREATION}

Arthur Koestler (1905-1983), the earliest of the triad, is primarily known as a novelist, the author of The Gladiators (1939), Darkness at Noon (1941), The Yogi and the Commissar (1945), and many others. Koestler's views on humour are expressed most extensively in his voluminous tractate The Act of Creation (1964). But the treatise of humour constitutes only about one-seventh part of the book, its proper topic being creativity. According to Koestler, creativity constitutes a kind of triptych consisting of three broad areas - humour, discovery and art. All of them are founded on bisociation bisociativity, i.e. the specific, conceptually "twoplaned" nature of any creative act. In the case of humour, it means comic collision of or oscillation between two frames of reference $\sim$ worlds of discourse $\sim$ codes $\sim$ associative contexts, in the case of scientific discovery - objective analogy, in the case of art - the image. The three types of creator are respectively the jester, the sage, and the artist, and the three "emotional moods" corresponding to the types of creativity are aggressive in the case of humour, neutral in the case of discovery, and sympathetic, admiring or tragic in the case of art. Whether the bisociative collision and switch result in a joke, solution of a logical problem or scientific discovery, a metaphor or sublime or tragic experience, depends on the specificity of situation, content of the recipient's memory, his/her emotive state and structure of values, etc. 


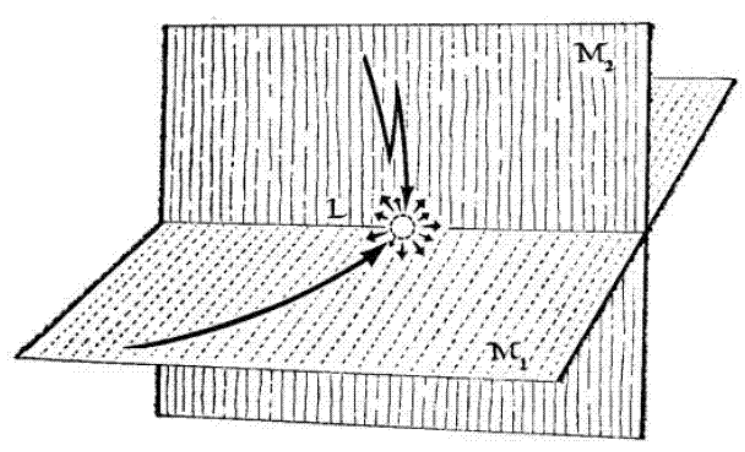

To Koestler's mind, humour involves a paradox, because laughter is a universal physiological reaction to a very great variety of different complex intellectual and emotional stimuli. So he evidently seems to share the view that humour cannot be grasped in a single conception or theory. Nor is Koestler's own theory of humour purely bisociative, but includes obvious elements of superiority $\sim$ degradation, as well as psychoanalytic theories. Koestler argues that humour is motivated by aggressive and/or apprehensive, self-defensive or assaulting impulses, and laughter is said to be an act of overt or covert unloading of these impulses. Our biological evolution, he says, has fallen dangerously behind our mental development. Aggressive-defensive emotions descend from our neurobiological "deep layers" and have greater persistence and inertia than our evolutionarily later developed flexible reasoning. Therefore a sudden bisociation of a mental event with two habitually incompatible matrices $\sim$ associative contexts $\sim$ frames of reference causes a sudden jump from one matrix to another, but our emotions cannot follow such quick toggling and so our psychological tension finds the solution in laughter, i.e. along the "channel of least resistance".

The major achievement of Koestler's book is pointing out the idea of bisociation itself, i.e. discovering the enormous importance and universal role that projections between different regions of experience play in human thinking and communication. It is not difficult to notice deep analogy between humour and metaphor, therefore it is no surprise that Gilles Fauconnier and Mark Turner (2002: 37 ), the world-famous cognitive theorists of metaphor have highly appreciated Koestler's "idea that creativity involves bringing together elements from different domains", so do also Belgian cognitive linguists Geert Brône and Kurt Feyaerts (2003: 1): "he inquires into the common cognitive grounds of highly disparate phenomena like humor, artistic creativity and scientific discovery", as have done already much earlier linguist G. B. Milner (1972: 11) and social anthropologist Ragnar Johnson (1976: 205-206).

But Koestler has received surprisingly little attention on the side of the 'proper' humour theory, even though the latter has been permanently in short of some broader theoretical framework to locate itself, and the common denominators 
'creativity' and 'bisociativity' of Koestler's constructions could well have been promising keywords for pursuits of the kind and, perhaps, would have facilitated recognizing the deep proximity between humour and metaphor and initiated the study of their relationships much earlier. The few authors who credit Koestler's contribution to inquiring into the more general cognitive roots of humour are, for example, Peter L. Berger (1997: 61 ff.) and Roy E. Russell (2000). As far as I know, only monographs by Michael Mulkay (1988) and Robert L. Latta (1999) include extensive parts dedicated to Koestler's work. Mulkay willingly accepts the very idea of bisociation, but finds Koestler's theory incapable of fulfilling the role of a general theory of laughter: laughter is not so uniform, reflective, or automatic response to various stimuli as Koestler suggests but much more variegated in many respects, often socially regulated, often altogether not aggressive or apprehensive, and so on. R. Latta, a seldom cited author from Kyoto, has proposed a socalled "Theory L" that can be qualified as a late variant of release theories. Latta's stance to Koestler is remarkably twofold. On the one hand, Latta (1999: vii) directly admits that his own theory "has its origins in Arthur Koestler's theory of humor". Yet, on the other hand, all the pathos of his book is directed against incongruity as a term and concept; instead of opposition or 'clash' between the two bisociated planes of meaning he prefers to see merely cognitive shift from one to another. So Latta's ardent aim is to prove that "Koestler's basic account is not in any sense a form of incongruity theory, though it is a form of cognitive-shift theory" (1999: 226).

More frequently, though, comments on Koestler's theory are superficially positive, but very brief - see e.g. Patricia Keith-Spiegel (1972: 17, 18, 19, 23, 29, 32); Paul E. McGhee (1979: 12); Mahadev Apte (1985: 239, 274); Salvatore Attardo (1988: 352, 358; 1997: 397); Alison Raju (1991: 75-76); Elliott Oring (1992: 145, 151); Seppo Knuuttila (1992: 119-120); Neal R. Norrick (1993: 8-9); Charles R. Gruner (2000 [1997]: 14, 151, 155); Robert R. Provine (2000: 17); Graeme Ritchie (2001: 122); William F. Fry (2002: 321); Mark C. Weeks (2002: 390). John Morreall (1987), Christie Davies (1990; 1998), and even Victor Raskin (1985) pass Koestler without a single notice.

Nevertheless, theory of humour is the only area of research where Koestler is considered a classic. In theory of literature, philosophy, even theory of creativity he is near to nobody. I will not speculate on the reasons because they obviously fall outside my subject. Perhaps they are partly hidden in his extraordinary personality and biography. David Cesarini, one of Koestler's biographers, has called him 'the homeless mind'. The same seems to apply to The Act of Creation in the world of humanities.

\section{VICTOR RASKIN'S SCRIPT-BASED SEMANTIC THEORY OF HUMOUR (SSTH)}

Another important figure in our triad is Victor Raskin, particularly so with his seminal book Semantic Mechanisms of Humor (1985) which may be the weightiest contribution to the incongruity theory of humour of all times. 
Raskin's monograph begins with introductory parts concerning the essence of humour, components of the so-called humour act, basic concepts and terms used in humour research, the 'kinds of laughter' and problems of categorizing humour itself and humour theories, etc. Raskin is the first to overtly identify his approach to humour as linguistic. This explains the presence of extensive chapters elucidating the development of linguistics (particularly formal semantics and pragmatics) in the 1960s and 1970s - the cornerstone concept of grammaticality in Noam Chomsky's theory of language; ungrounded faith in capabilities of statistical methods in early mathematical linguistics; notions of presupposition, implicature, possible worlds, speech acts; attempts to create formalized semantic theories by Jerold Katz and Jerry A. Fodor, and criticism of these theories by Uriel Weinreich, James McCawley, George Lakoff, Raskin himself and others; rise of pragmatics in the theory of language; need for inclusion of contextual information and encyclopaedic knowledge; autonomous vs. non-autonomous semantics; competence vs. performance; the concepts of script $\sim$ schema $\sim$ frame, the inner structure and types of them; the so-called combinatorial rules for relating scripts and collocating them to semantically compatible meaningful units; the criteria and procedures for justification and evaluation of a semantic theory.

Understandably, then, Raskin's script-based semantic theory of humour (SSTH) does not aim to cover humour in general, but only verbal humour (or in practice, only punchline jokes), and understandably also, it reflects the state of affairs in linguistics at the end of the 1970 s, i.e. at the moment when the crisis of formal semantics had reached its peak and conditions were ripe for the upcoming cognitive breakthrough. So the ultimate goal of the SSTH was set down as follows: "Ideally, a linguistic theory of humor should determine and formulate the necessary and sufficient linguistic conditions for the text to be funny" (Raskin 1985: 47).

The core part of Raskin's book consists of theoretical and empirical chapters (four, and five to seven, respectively). I will briefly introduce the principal constituents of the theoretical part (Chapter Four).

1. The main hypothesis of the SSTH is the following:

(107) A text can be characterized as a single-joke-carrying text if both of the conditions in (108) are satisfied. (108) (i) The text is compatible, fully or in part, with two different scripts (ii) The two scripts with which the text is compatible are opposite in a special sense defined in Section 4. The two scripts with which the text is compatible are said to overlap fully or in part on this text. (Raskin 1985: 99).

2. The postulate about joke-telling as a specific kind of "non-bona-fide" communication which violates the Cooperative Principle and the so-called conversational maxims set for the "bona-fide" (i.e. usual, information-bearing, serious, sincere) communication in Gricean pragmatics. In the case of joke-telling four different situations may occur, depending on whether the speaker makes the joke intentionally or unintentionally, and/or whether the hearer expects or does not expect 
the joke. If the receiver does not assume a joke, he/she would try to understand what was said in a default bona-fide way and, after a failure to do so, seek some other, non-bona-fide mode of interpretation (joke, lie, nonsense, etc.). If an addressee is already from the beginning or after the switch-over attuned to the "joke wave", the Cooperative Principle starts to operate again, but in a specific "joke-oriented" manner and with modified maxims, e.g. "Give exactly as much information as is necessary for the joke" instead of the usual Maxim of Quantity, "Say only what is compatible with the world of the joke" instead of usual Maxim of Quality, etc. (Cf. below also Salvatore Attardo's sharply different views on violation of maxims in humour.)

3. Explication of the relationships of the scripts involved 'script overlap' and 'script opposition'. Raskin gives empirical examples of semantic common parts perfectly compatible with both scripts under discussion, and others that fit naturally with one script but only conditionally with the other. Some of the jokes' script oppositions are usual antonymous (contradictory or contrary) oppositions, but the bulk of them seem to be what John Lyons has called local antonyms, i.e. "linguistic entities whose meanings are opposite only within a particular discourse and solely for the purposes of this discourse" (p. 108). Each joke describes some "real" situation and evokes another, "unreal" situation. They can be manifested as oppositions between the 1) actual and non-actual, non-existing situation, 2) expected and abnormal, unexpected states of affairs, 3 ) possible, plausible and impossible, less plausible situation (p. 111). And the scripts evoked by jokes often involve some binary categories which are essential to human life, like real/unreal, true/ false, good/bad, death/life, obscene/decent, rich/poor, etc. (p. 113-114). Many jokes contain special semantic script-switch triggers that highlight the need for substituting scripts, the two main types of such triggers are ambiguity and contradiction.

4. The analysis of the "bronchial patient" joke:

"Is the doctor at home?" the patient asked in his bronchial whisper. "No," the doctor's young and pretty wife whispered in reply. "Come right in."

This is Raskin's favourite example, also largely reiterated and discussed by later authors, which he uses many times, e.g. for explaining the overlap and opposition of incongruous scripts (pp. 32 and 104-105): the joke includes scripts of (VISITING THE) DOCTOR and (VISITING THE) LOVER; the scripts are linked via the component of whispering compatible with both. Wife's invitation to come in rudely violates the Maxim of Quantity and acts as a trigger for shifting from the first script to the second. Further (pp. 117-127) Raskin once more gives the full and scrupulous "from under to up" analysis of the joke. The format of the background semantic theory he uses for the analysis consists of two components - the lexicon, and the combinatorial rules to derive semantic interpretations of full sentences from meanings of their lexical components (p. 76). Following this routine, Raskin takes to input the (sub)meanings of all the words of the joke text (be,doctor, at, home, etc.) in Webster's Dictionary, sketches the rules for disambiguating clauses, and summarises an interpretative paraphrase for the first sentence of the joke: 
"Somebody who was previously treated for an illness wants to know whether the unique proprietor of a family residence [who is a physician] is physically present in the residence" (p. 122). A similar analytic representation is also created for the second sentence and all possible presuppositions and inferences drawn from either sentence. So the interpreter is led to the crucial question: "Why does the doctor's wife want the patient to come in?", and the only answer the combinatorial rules are able to give on their own is: the wife fails to understand that by coming to the doctor's home the patient will not meet the doctor and thus will not reach his aim (p. 124). The next and the most critical step - a leap from the failed script to a suitable alternative - remains totally outside the capacities of combinatorial rules and the receiver will be able to achieve it only through intuitive trial and error, using his/her encyclopaedic knowledge, or WORLD INFORMATION, as Raskin calls it. Knowledge of this kind acts as a certain deus ex machina which can be addressed wherever necessary and has been already addressed elsewhere (e.g. to choose between the congruent submeanings of a text's lexical constituents and to derive some inferences). True, Raskin chalks out a block-schema of combinatorial rules for searching the appropriate second schema as well ( $\mathrm{p}$. 125), but as the criteria of that match remain semantically blind, the proposed strategy of search reminds slightly of the notorious instruction for fitting four elephants into a Mini.

Like notions of conceptual domain, schema and mental space in cognitive linguistics, Raskin's concept of script is also merely a loose and coarse approximation of what actually happens in human consciousness at the neural level. Raskin's scripts thereat are of various kinds in very various aspects. Associative connections between words have different density, therefore the "semantic distance" between different word scripts can be conceived as closer or farther. Scripts encapsulate not only "direct" word meanings, but also semantic information presupposed by or inferred from linguistic units. Besides, not only linguistic, but also extralinguistic (encyclopaedic) knowledge is allegedly stored in our memory in the form of scripts. Further, scripts encapsulating this non-linguistic knowledge may be of individual, restricted or general scope. There exist elementary, non-elementary and metascripts, etc. (see pp. 134-139; cf. also Attardo 1994: 246 ff.).

Certain conditionalities concern also relating scripts with their linguistic representations. The problem is somewhat analogous to that of the markup of the socalled conceptual metaphors in the works of the Lakoffian cognitivist school of thought. Such metaphors can be sometimes designated with various kinds of A IS (A) B -sentences (TIME IS MONEY; PEOPLE ARE PLANTS; LIFE LOVE IS A JOURNEY; GOOD IS UP / BAD IS DOWN; DEATH IS GOING TO A FINAL DESTINATION; HARM IS PREVENTING FORWARD MOTION TOWARD A GOAL), but sometimes marked with very loose and generalized "headings" (CONDUIT METAPHOR, CONTAINER METAPHOR, EVENT STRUCTURE METAPHOR, GREAT CHAIN METAPHOR, DIVIDED PERSON METAPHOR). The same holds for Raskin's incongruous joke scripts: they are sometimes marked with single proper nouns (stalemate vs. wife), sometimes with deverbal nouns (good performance vs. bad performance), sometimes with propositions (senators are gentlemen vs. senators are not gentlemen), or otherwise. Particularly in the 
second empirical part of Raskin's book (Chapters Five to Seven) the concept of script is given such a broad and "impressionistic" meaning that it could be safely replaced with some more conventional term like theme or motif.

In these final chapters the proportions between author's text and joke examples have also changed radically in favour of the latter: Raskin had a huge stock of Soviet and other joke texts at his disposal, but too little of space to analyse each of them thoroughly. Here the three main kinds of "aggressive" humour are introduced - sexual, ethnic and political. Raskin points out the most salient scripts (themes, motifs) and types of oppositions encountered in each category and illustrates these with numerous examples.

Sexual humour, Raskin says, can be divided in four main types:

1) sexual/non-sexual opposition: overt, unspecified;

2) sexual/non-sexual opposition: overt, specified;

3) non-sexual opposition in explicitly sexual humour;

4) specific sexual opposition in explicitly sexual humour.

I must admit that the criteria for differentiating the types and for categorising a certain text item under one particular type or another remained partly vague to me. Therefore I will not at this point go into details of this complicated matter, but will delineate only my personal (perhaps erroneous) understanding of it. The essence of the first type lies in inserting a blue hint or allusion into sexually neutral context. One of Raskin's own examples is:

An English bishop received the following note from the vicar of a village in his diocese: "Milord, I regret to inform you of my wife's death. Can you possibly send me a substitute for the weekend?" (Raskin 1985: 106).

The second type superimposes something sexually abnormal $\sim$ hyperbolic $\sim$ vicious $\sim$ unexpected onto something normal $\sim$ accepted $\sim$ expected. The most frequent kinds of these abnormalities that Raskin also calls scripts are, e.g., GENITAL SIZE, SEXUAL PROWESS, SEXUAL EXPOSURE, SEXUAL IGNORANCE or INEXPERIENCE, various instances of FORBIDDEN SEX (zoophily, adultery, prostitution, incest, same-sex intercourse). Here is a short example on oral sex borrowed from Legman:

The mother tells the little girl that the little boy's penis is a whistle. "No, it ain't. I blew it all afternoon and I couldn't get a sound out of it." (Raskin 1985: 159).

In the third type, as a rule, the hearer's expectations are primed towards the sexual output of the joke but are thereafter deceived. True, not all Raskin's examples follow the rule as perfectly as the one below does:

An officer is posted to a god-forsaken garrison. After a while, he asks his batman who has spent a few years there, "What do you do for sex? There isn't a single woman here." - "Oh, Sir, we all use the old camel over there." - 
"Really? Officers too?”- "Yes, Sir.”After much hesitation, the officer decides to try it. That night he comes back to his quarters, dishevelled, dirty, and frustrated. "How do you all manage it? The camel does not seem to be used to it at all. She threw me off each time I tried." - "We use the old camel to get to the village six miles from here, Sir.”(Raskin 1985: 161).

The only difference of the fourth type from the second type seems to lie in the fact that in the latter the joke starts in a sexually neutral key, but in the former events are situated in the sexual domain from the very beginning. An illustrative example is the following:

A nun is attacked and raped by twelve bandits in the desert. When they are done with her and flee the nun stands up and says, "That was nice. Enough and sinless." (Raskin 1985: 167).

(To my personal opinion, folkloric obscenities (in jokes, riddles, metaphors or elsewhere) are being handled in two opposite ways: either something actually decent is displayed as obscene or something actually obscene is displayed as decent. This general notice would allow to slightly reinterpret Raskin's four types of structuring sexual humour.)

The specific scripts of ethnic jokes are predominantly focused on certain features or peculiarities of personality, conventionally and fictionally assigned to the targets of ethnic mockery (or exceptionally, also ethnic approval). The most universal of them are negatively labelled scripts of LANGUAGE DISTORTION, DUMBNESS, and STINGINESS (pp. 181-191). The script of CRAFTINESS, or CUNNINGNESS, on the contrary, has axiologically dual character: it is closely related with the script of DECEPTION but, on the other hand, presumes a nimble mind and as such "may command some reluctant admiration" (p. 191). Raskin does not recall here the generally known fact that in older humorous "non-punchline" folk tales and fables craftiness, successful lying and deception were appraised as unreserved virtues. Ethnic humour often engages also specific sexual and other scripts, thus constituting complex scripts like OVERSEXED MINORITY for the Soviet Georgians, HOMOSEXUALITY for Soviet Armenians, HYPERSEXUALITY for the French, as well as ASEXUALITY, METHODICITY and BLIND OBEDIENCE for the Germans, RESPECT FOR TRADITION and COLD POLITENESS for the British, etc. (pp. 194-200). The so-called national superiority jokes, in turn, tend to be intermingled with political issues (pp. 202-205). The properly ethnic jokes, Raskin stresses, should not be confused with pseudo-ethnic ones that can be construed incidentally and ad hoc: a truly ethnic joke must include at least one truly ethnic script and the interchangeability of ethnic agents is considerably restricted (pp. 205-209).

Works on humour by Jewish authors usually include a part devoted to Jewish humour, and so does the work of Raskin (pp. 209-221). Rich and original Jewish humour has generated a large number of specific scripts. Of standard ethnic scripts CUNNINGNESS and STINGINESS, in particular, are traditionally ascribed to the Jews. Jokes based on these scripts can be told by others about Jews, as well as 
by the Jews themselves about themselves. Anti-Semitic jokes not told by the Jews themselves also include scripts of COWARDICE and UNCLEANINGNESS, and these told by the Jews themselves include scripts of ANTISEMITISM or POGROM (sometimes developed into JEWISH vs. GOYISH script), and SMARTNESS (often developed into SOPHISTICATED JEWISH LOGIC, WISE FOOL and NONONSENSE scripts).

Political jokes in Raskin's book (pp. 222-246) are divided in two classes - denigration jokes and exposure jokes. The basic scripts that represent the first class are DENIGRATION OF A POLITICAL FIGURE (showing him as stupid, indecent, unpopular, hated), DENIGRATION OF A POLITICAL GROUP OR INSTITUTION (usually also by means of criticizing some impersonalized member(s) of it), and DENIGRATION OF A POLITICAL IDEA OR SLOGAN (often in a fully impersonalized form of a dialogical riddle, like the so-called Armenian Radio jokes). Political humour intersects with ethnic humour, the EXPOSURE OF NATIONAL TRAITS being a typical representative of it, e.g. with the scripts of DUMBNESS, BLIND AND HYPOCRITICAL OBEDIENCE, PRACTICALITY and RATIONALITY in Raskin's examples (pp. 231-232). Other types of exposure in political jokes are EXPOSURE OF POLITICAL REPRESSION (terror and arrests, the lack of political freedom and civil liberties, viz. freedom of speech), EXPOSURE OF SHORTAGES (especially in the former Socialist countries), and EXPOSURE OF SPECIFIC POLITICAL SITUATIONS (understanding them often presupposes specific encyclopaedic knowledge about certain historical events, peculiarities of specific political regimes, etc.). The last subchapter of Raskin's book summarizes the distinctive features of Soviet political humour.

\section{THE GENERAL THEORY OF VERBAL HUMOR (GTVH)}

I have no knowledge as to when and where exactly Victor Raskin and Salvatore Attardo met each other for the first time. In 1973, Raskin emigrated from Moscow to Israel; in 1978 he started working at Purdue University in the United States. Salvatore Attardo, a linguist of Italian origin, began working at the same university about ten years later. In 1991 he defends his $\mathrm{PhD}$ thesis From Linguistics to Humor Research and Back: Applications of Linguistics to Humor and Their Implications for Linguistic Theory and Methodology under Raskin's supervision. Since 1994 he has been working at the Youngstown State University. Beside the theory of humour, the areas of his expertise include pragmatics, semantics, sociolinguistics, and computational linguistics.

One of the works Raskin and Attardo have published jointly is "Script theory revis(it)ed: joke similarity and joke representation model" (1991). The article aims to integrate Raskin's script-based theory (SSTH) with the five-level representation model of jokes outlined in the earlier works by Attardo. As the result, the sixlevel hierarchical representation model of verbal jokes is proposed which pursues to be, at the same time, a device for evaluating the "semantic distance", or degree of similarity between particular joke texts. The empirical testbed of the model is limited to seven variants of the well-known light bulb joke, some of them being 
taken from real sources, others obviously improvised by the authors themselves. Each variant allegedly differs from others exactly in one particular KR.

The hierarchy of the knowledge resources is as follows:

1. Language (LA). "It includes all the choices at the phonetic, phonologic, morphophonemic, morphologic, lexic, syntactic, semantic, and pragmatic levels of language structure that the speaker is still free to make, given that everything else in the joke is already given and cannot be tinkered with" (p. 298), or further: "...basically, it is the content of the joke which has to be expressed within the parameter of language" (ibidem), and still further, even: "parameter of language is responsible for exact wording and placement of the punchline" (p. 299). Or, in simplified perspective, the LA level is considered responsible for any change not delegated to some higher level KR.

2. Narrative strategy (NS). This means "the genre, or rather microgenre [---] of the joke, in other words, whether the text of the joke is set up as expository, as a riddle, as a question-and-answer sequence, and so on" (p. 300). The joke also can be expanded to a longer dialogue, customary to folk narratives triple sequence can be constructed, the newspaper advertisement form applied, etc. When building the narrative strategy, it is important to keep the text sufficiently nonredundant in order not to spoil the punchline (cf. about this danger also Raskin 1985: 145; Oring 1992: 90).

3. Target (TA) is the personalized "object" (individual and/or member of a group) of the joke. Attardo \& Raskin (pp. 301-302) provide examples of the rich choice of ethnically, socially or politically marked personages who have been considered apposite to fulfil the role of targets in the light bulb joke. They admit that the number of jokes without clear targets is quite small, but emphasize the exclusively conventional character of ethnic or other choices for embodiments of stupidity and deny any correspondence between such stereotypes and reality.

4. Situation (SI) consists of the rest of the content constituents or "props" of the joke, like other participants beside the target, activities, objects, instruments, etc. For example, the stupidity of the Polish can be manifested in many "synonymous" ways: several bizarre modes of screwing the light bulb, holding the toothbrush and moving one's head, holding the fan and shaking one's head, turning the car upside down to empty the car ashtray, etc.

5. Logical mechanism (LM). This has proved the most problematic element in the GTVH model (for further discussion, see also here below). Here, "logical" does not stand for deductive logic or strict formal logicality but rather should be understood in some looser quotidian sense 'rational thinking and acting' or even 'ontological possibility'. For example, the usual reverse method of bulb-screwing has proved successful and is therefore "fully justified logically", the reverse method of car washing is "somewhat faultier logically", but the method of emptying the ashtray and turning the ceiling instead of the table in the bulb joke are "equally faulty" (pp. 303-304). The common LM for the whole joke series under discussion is called figure-ground reversal. More generally, whatever manifestations of false 
logic are being placed at the LM level, including other kinds of reversals and chiasms with ABBA mirror structure, false analogy and false priming (i.e. usages of the so-called 'garden path technique'), tricks made by means of polysemy and homonymy in puns. In this subsection there is also a brief reference to E. Aubouin's discussion on justification of the absurdity and pseudo-logic in jokes and to Avner Ziv's famous notion of "local logic".

6. Script opposition (SO). This is the only level of Raskin's SSTH incorporated into the GTVH model. The authors find the oppositions of the lowest level in SSTH not to be equal in generality and put forward proposals to overcome this shortcoming (inadequate, to my mind, at least on the part of the status of the axiological 'good/bad' opposition that seems to engage an universal, fundamental and omnipresent status in any human communication, thinking, and cognition of the world). Despite knowing well the alternative ways of categorizing, proposed by Lofti Zadeh, Eleanor Rosch, George Lakoff and others, Attardo \& Raskin are hardly convinced that the hierarchical structure is the most suitable for the GTVH model. True, some alternatives are pondered, but then categorically rejected - for example, radial dislocation of KRs around the joke (p. 314), or dividing of the categories to a smaller number of levels, e.g. (SO \& LM) -> (TA \& SI) -> NS -> LA (p. 320), or eventual dividing of them only to "content-oriented" (SO, TA, SI) and "tool-oriented" (LM, NS, LA) groups (p. 322). The most serious motivation for preferring the linear hierarchy probably lies in abovementioned hope to use KR sequence ladder in measuring the "psychological distance" between different joke texts, LA thus being the weakest and SO the strongest differentiator. On the other hand, it is strongly emphasized that GTVH does not aim to be a model of the real "online" production of jokes, but is merely an analytical construct.

Willibald Ruch, the distinguished German psychologist and humour researcher, has organized a test experiment on 534 subjects to verify the validity of two hypotheses derived from the GTVH: "first, the subjects will perceive some jokes as more similar and other jokes as less similar to one another; second, if the GTVH is correct, subjects will perceive a linear increase of similarity between pairs of jokes selected along the KR hierarchy". That is, jokes differing in LA were expected to be more similar than those differing in NS, the latter ones more similar than jokes differing in TA, and so forth (see Ruch et al. 1993: 127-128). The material used in the experiment consisted of three sets of "somewhat synonymous" jokes - first, the already mentioned light bulb set, second, a set of blonde jokes, and third, the joke about chicken crossing the road, with seven texts in each set, each text assumed to differ from others exactly in one KR level. The similarity of text pairs was evaluated on the five-point scale. After the test, the averages of "distinguishing power" for each KR-position in each particular joke series, as well as total averages through all three series were calculated and the validity of differences tested via ANOVA. Three lowest KRs appeared to follow theoretical expectations both in the plane of rank sequence (LA -> NS -> TA) and linearity of regression, but the three highest ones displayed an unexpected order of sequence: not SI -> LM -> SO, but LM -> SO -> SI (however, with insignificant difference between the latter two). Ruch et al. (1993: 132 ff.) propose three conjectures about reasons of this disorder: 


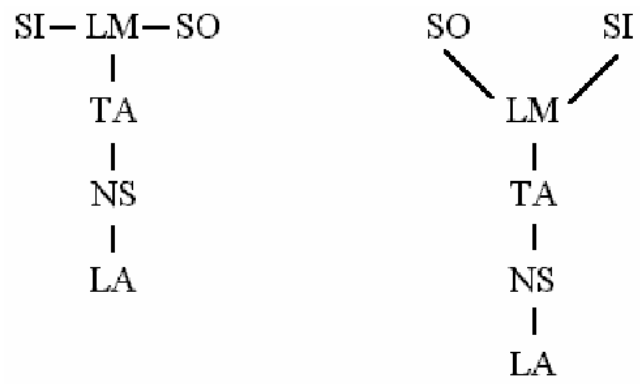

1) the postulated sequence of KR ranks of the GTVH model is factually wrong and the model needs to be restructured - e.g. as shown in the figures below (cf. pp. 132-133):

2) "as Attardo and Raskin (1991) highlighted, the LM is the least explored of all KRs and that there could be several factors at play which might have influenced the subjects' perception" (p. 133);

3) "in fact, the LM is an artefact of the theory and should be removed altogether" (ibidem).

Considering all possible reservations as to scantiness and heterogeneity of the test material, conceptual indefiniteness of the KRs (especially LM), their laddershaped structure, etc., the output of Ruch's experiment appears not at all surprising from the point of view of traditional folkloristics. Leaving aside the LM with its really vague identity, there is a good reason to assume that judgments made by the test subjects were guided by intuitions about jokes as emic (or typological, in customary folkloristic slang) units, or to put it more simply, whether or not the texts compared in pairs were perceived as variants of the same joke. Perhaps the subjects' intuition reduced all the differences between test texts to "formal" changes (that did not destroy the impression of their typological sameness) and "content plane" changes (that impelled to perceive them as typologically distinct). From this perspective, the pondered, but rejected division of KRs to "content-oriented" (SO, TA, SI) and "tool-oriented" (LM, NS, LA) groups might look perfectly reasonable.

\section{ATTARDO’S ISOTOPY-DISJUNCTION MODEL OF JOKES (IDM)}

Chapter Two of Attardo's first monograph Linguistic Theories of Humor (1994) is concerned with developing a theory of linear organization of jokes (IDM) that he had started already in his early works in Italian. One of the theoretical cornerstones of the IDM is the concept of isotopy borrowed from Sémantique structurale (1966) by Algirdas Julien Greimas. For the introduction, Attardo briefly touches upon the whole terminological apparatus of Greimas' theory: seme, sememe, classeme, immanence and manifestation of semes, lexeme, semic nucleus, actual 
and virtual functioning of classemes, transitions from phrastic to transphrastic units of texts, processes leading to the establishment of isotopies (expansion, condensation, translation, figuration), complex isotopies, and so forth (pp. 65-73). Greimas' isotopies are essentially nothing else than different readings of ambiguous expressions that can be encountered anywhere and Greimas is engaged with deductive general semantics, not with theory of humour. But one of the examples Greimas uses to illustrate his theory is a joke punning with two meanings of the French word toilettes ('lavatories' vs. 'women's attires'), and this has inspired some European authors (Violette Morin, Patrick Charaudeau, Franz Joseph Hausmann, Pierre Guiraud, etc.) to apply Greimas' constructions and terminology to analysis of narratives, including jokes. According to Greimas, in the course of understanding the joke on toilettes, a transition from one alternative meaning (isotopy) to another must take place, so the jump between isotopies appears to be closely synonymous with Koestler's clash of bisociative matrices, or Raskin's switch of opposed scripts, or leap from one frame to another in Seana Coulson's later work (1997).

Attardo accepts, on the principle, the triplet of narrative functions proposed by V. Morin - normalization, interlocking, and disjunction - which aims to grasp the linear, syntagmatic organization of narratives (pp. 85 ff.). Understanding a transphrastic cohesive text in any case presumes its semantic disambiguation. But disambiguation of a punchline joke, as Attardo notes, differs in principle from that of a non-humorous text. When the first isotopy $\left(\mathrm{S}_{1}\right)$ is established, the receiver will continue the interpretation in the same spirit, until he/she encounters the semantic barrier that can be overcome by shifting to the other, antagonistic isotopy $\left(S_{2}\right)$. Attardo refers to the element that causes the $S_{1}->S_{2}$ passage and sets off laughter as disjunctor. Disjunctor operates closely with another element, the connector, that embodies (with certain restrictions that will be mentioned below) the "common part" of the isotopies scripts $\sim$ frames and provides playful justification for such a passage. Attardo divides the jokes to verbal and referential ones.

The former are based exclusively on the meaning of the text and do not make any reference to the phonological realization of lexical items (or of other units in the text), while the latter, in addition to being based on the meaning of the elements of the text, make a reference to the phonological realization of the text (Attardo 1994: 95).

Practically, it means that referential jokes are translatable from one language to another in principle, whereas verbal jokes are translatable only incidentally and exceptionally. Verbal jokes, in turn, can be based on phonic or syntactic ambiguity or alliteration. Below are some examples of each kind:

Phonic ambiguity (the pun):

Q[uestion]: Do you believe in clubs for young men? A[nswer]: Only when kindness fails. (Attardo et al. 1994: 28; Attardo 1994: 97 and passim). 
Syntactic ambiguity:

The big game hunter was telling about his adventures to a group of school children during their show-and-tell period. In describing some of his exciting experiences in Africa he said, "On night I remember being wakened by a great roaring noise. I jumped up and grabbed my gun, which was always kept loaded at the foot of my cot. I rushed out and killed a huge lion in my pajamas." At the close of his presentation he asked if there were any questions. "Yes," said a little girl sitting on the front row, "how did the lion get into your pajamas?” (Attardo et al. 1994: 34).

Alliterative joke:

Today's tabloid biography: High chair, high school, high stool, high finance, high hat-hi, warden! (Attardo 1994: 139; Attardo et al. 1994: 36).

Attardo resolutely claims that only verbal jokes include connectors: "Referential humor does not have a connector" (p. 96, note 34 ). If the recipient of a verbal joke comes across the incompatible with the initial part element (disjunctor), he/she will backtrack the text to find a possible ambiguous lexeme (like clubs in the pun above) and that way another, cohesive interpretation. But obviously, some analogous "linking element", if not merely a lexeme, should probably be found in any referential joke as well. True, with references to E. Aubouin and A. Ziv, Attardo speaks about the function of justification, that is, "a playful motivation for the presence of the second sense" (p. 97). But obviously, again, justification is not a counterpart of the connector in referential jokes. Thus, the conceptual status of the connector remains relatively cryptic.

Alone and together with his colleagues/students, Attardo has made several observations to test the following four hypotheses against Italian and American empirical materials (see Attardo 1994: 101-102; Attardo et al. 1994: 30):

a) referential jokes outnumber verbal jokes;

b) within the set of verbal jokes, puns outnumber all the other categories (i.e. syntactic and alliterative jokes);

c) the position of the disjunctor is final;

d) within the set of verbal jokes, the jokes in which the disjunctor follows the connector outnumber the jokes in which disjunctor and connector coincide.

The outcome turned out to be positive for all the hypotheses tested. I would like to briefly comment upon the first three of them. On the one hand, they look perhaps too acceptable to need any proof. On the other, the explanations of some results appear problematic. For example, it is supposed that referential jokes outnumber verbal jokes simply because the former are being deliberately preferred to the latter. Much sooner, though, spontaneous natural causes might be supposed to have been at work here: probably, the proportion of borrowed inter- 
national material in the tested sources was relatively high which could have made the prevalence of referential jokes almost trivial and automatic, because the translinguistic filters let pass virtually all referential jokes, but closed off virtually all verbal jokes. Attardo et al. (1994: 41) neatly summarize the general rule for locating the punch line in the joke "... the punch line of the joke is the rheme of the last sentence of the text of the joke". Next to various "semantically empty" random additions and comments that can occur after the punch line, there is an interesting exception - the so-called multiple punch lines. What are meant here are not the jokes with tripartite structure (like the well-known "jokes with three nationalities"), but jokes with a monotonous chain structure without any salient or dissonant chain, for example:

The workers in my company formed a union and want to share in what I get from the business. So I agreed. I gave one an ulcer, one a migraine, one hypertension, and the rest high blood pressure. (Attardo et al. 1994: 43).

\section{ATTARDO: THE ANALYSIS OF PUNS}

The next two chapters in the monograph by Attardo (1994: 108-173) are dedicated to the closer analysis of puns.

He starts by suggesting that puns have been one of the few tangential points between linguistics and humour studies, but regardless of that they have largely remained an unmapped area of research. Beside verbal puns, there are also visual puns, puns made in deaf sign language, etc. Lexical or other sign sequences which the puns are ordinarily based on are paronyms (phonically similar, but not identical units), homonyms (phonically and/or graphically identical), homophones (phonically identical), and homographs (graphically identical) (pp. 109-111).

Attardo complains that most of the efforts of structural linguists have been focused on creating taxonomies of puns, although taxonomies do not have sufficient predictive and explanatory power and therefore cannot replace analysis and theory building (pp. 111-112). Despite that, he also makes an attempt to construct the "taxonomy of the taxonomies" of puns which results in the following categories (see pp. 112-127):

1) taxonomies based on linguistic phenomena (homonymy, polysemy, antonymy, etc.), e.g. the one proposed by Otto Duchaček;

2) systematic taxonomies based on very general linguistic categories (e.g. by G. B. Milner, F. J. Hausmann, P. Guiraud), usually distinguishing between the paradigmatic and syntagmatic axes on the upper level of classification;

3) taxonomies based on surface structure (e.g. by F. J. Hausmann, Arnold \& Ann Zwicky, W. Sobkowiak) which aim to measure the "phonemic distance" between the puns involved;

4) eclectic taxonomies (e.g. by M.-B. Vittoz-Canuto). 
Further (pp. 128-131) Attardo gives an analysis of two isotopies in a particular example of pun - "Why did the cookie cry? Its mother has been away for ( a wafer) so long". The initial contradiction will be eliminated and the text disambiguated via personification of the cookie, but the result is still boring, lacking any "pragmatic weight" and humour, so the receiver must continue the exploration until discovering the alternative meaning of "a wafer" from behind the ambiguous string of sounds. Unfortunately, it remains unclear just what is the good reason for a wafer's child to cry - the low stature of the mother? With references to Pierre Guiraud, Attardo also discusses "the fate of the first interpretation" after the other "correct" interpretation has been found - will it be abandoned or will it survive and somehow coexist with the latter? Guiraud had considered four outcomes possible: 1) no relation; 2) both senses coexist; 3) $S_{2}$ forces connotation on $S_{1}$;4) $S_{1}$ forces connotation on $S_{2}$. According to Attardo, Guiraud's approach indirectly indicates the possibility of quality-based classification of puns: "the best puns are those in which either the two senses coexist in a difficult balance, or in which the connotating sense brings a meaningful contribution to the global senses of the text" (p. 138). In different parts of his book, Attardo has pointed out different views about the relative positions of connector and disjunctor, for example: "The disjunctor must necessarily follow the connector" (p. 99), but cf. elsewhere: “...either the two are realized by the same linguistic entity or they are not. In the first case, the connector and disjunctor are said to be non-distinct; in the second case they are said to be distinct" (p. 138). In the final part of Chapter Three Attardo lists eventual benefits linguistics could get from researching puns: evidence of psychological reality of phonic elements in language, evidence of pronunciation in diachronic linguistics, etc.

In the fourth chapter of his book Attardo deals with the problem of resolution in puns: is incongruity capable to produce humour on its own, or should it be necessarily followed by "resolution"? His discussion around the concept of resolution diffuses again into references to Aubouin's "justification" and Ziv's "local logic". There are two moments that Attardo (p. 144) considers important: 1) each humorous text includes an element of incongruity as well as an element of resolution; 2) the resolution may be playful, it must not be complete, realistic and plausible. By criticizing Aubouin's views on justification, Attardo begins to build up his own theory of puns, the key features of which are "cratylistic" and "metalinguistic".

Cratylos, one of Plato's teachers, was the earliest known representative of the theory of sound symbolism and believed sounds and senses to be related by natural law rather than by convention. To Attardo's mind, natural speakers share such a cratylistic naïve theoretical view towards language and defaultly assume the relationship between the signifiers and the signified to be motivated, treating homonyms as synonyms and believing sounds to convey semantic associations. Thus, if this could be valid for puns as well, one is justified to argue that "puns carry connotative semantic associations between the two senses involved in the pun", although "it is not claimed that these semantic associations are "real", or that the speakers are committed to their truth: these associations, and the corresponding resolutions, are playful, ludic ones" (p. 150). 
Further (pp. 154-158), Attardo tries to provide evidence about implicit manifestations of the "theory of motivated signs" in the minds of naive speakers: folk etymology (e.g. German Sauerkraut French choucroute), tabooing words (mainly for reasons of obscenity or magic), so-called folk linguistics, sound symbolism in poetry, the so-called linguistic iconicity (viz. in the famous example by Roman Jakobson big bigger the biggest). Attardo (pp. 158-160) meditates on how peculiar a fully motivated linguistic system would appear: all languages would be the same, i.e. there would be only one language; there should be a definite correlation between sounds and meanings; there can be no homonymy. Evidence for psychological reality of sound-based associations between lexical units are listed separately (pp. 160-163), including rhyme, speech errors and language pathology in general. The most convincing of them are the so-called clang responses, thoroughly studied in psychology: under normal circumstances the responses in word association tests predominantly follow semantic links between words, but adverse conditions (accelerated speed, performing several tasks simultaneously) notably increase the proportion of responses based on sound similarity (e.g. alliteration and assonance). The "spreading activation" model of word retrieval elaborated by Allan Collins and Elizabeth Loftus also corroborates the involvement of phonic factors in the retrieval processes.

But unlike the usual spontaneous and unconscious phenomena of cratylism, puns are conscious and deliberate, their users are aware of their peculiar cratylistic nature. To overcome this contradiction, Attardo dares to accept Franz Joseph Hausmann's challenge, making the following statement: "The conscious nature of Cratylism in puns can be reduced to the unconscious phenomena listed above by emphasizing the metalinguistic status of puns" (p. 168). Due to my helplessness to associate this statement with my previous knowledge about the concept of metalanguage, I simply quote here the substantiation of this statement from the original source:

Puns are metalinguistic because their decoding presupposes the presence of a metalinguistic assertion along the inferential processing involved in the decoding. The kind of metalinguistic information that is conveyed can be summarized as "this text is using a sign (i.e. any phonemic string) which, through some paradigmatic or syntagmatic association, evokes another sign; the meanings evoked by both signifiers are not mutually compatible in the context of the text." (ibidem).

Nor does the following passage render things clearer to me:

Since puns are metalinguistic, the use of an implicit Cratylistic theory of signs becomes acceptable to the speaker consciously because metalanguage suspends the rules of the object language, and so the speakers can justify (if they are disturbed by it) their unusual behavior in terms of its being "not for real."(ibidem). 
Against these backgrounds, however, Attardo appears to consider metalinguistic not the puns as such, but interpretative speculations about them that do not yet have any overt linguistic manifestation and their calling metalanguage is dubitable. He also appears to distinguish too sharply between verbal jokes (particularly puns) and other types of jokes and overemphasise the role of phonic aspect in the common part of the joke scripts. One can guess that there is, after all, a certain dissonance between some content components that make a joke what it should be, no matter which media is used to convey the incongruous information - translatable or untranslatable language, visual means or some combination of them.

\section{ATTARDO ON VIOLATION OF PRAGMATIC MAXIMS IN JOKES}

Writings on the pragmatics of humour by Attardo (1993, 1994: Chapter Nine) are focused on discussion about Paul Grice's Cooperative Principle and conversational maxims, mostly bypassing John Austin's "locutions" and other issues of the theory of speech acts. Attardo (1993: 538-539) briefly introduces the conception of rules of conversation in Grice's Logic and Conversation (1991 [1989]: 22-40) - Cooperative Principle, conventional and conversational implicatures, maxims, forms of violating them (viz. violating / opting out / flouting).

The problem of maxims is presented as a paradox. Jokes violate maxims so frequently that "the claim that all jokes involve the violation of (at least) one maxim of the CP is commonplace in humor research" (Attardo 1993: 541), but, just as obviously, jokes may contain and convey information without noticeable noise.

Attardo (1993: 541-542; 1994: 272) gives a dialogic example of each maxim-violation:

1) Quantity: "Excuse me, do you know what time it is?" - "Yes";

2) Relation: "How many surrealists does it take to screw in a light bulb?" -"Fish!";

3) Manner: "Do you believe in clubs for young men?" - "Only when kindness fails";

4) Quality: "Why did the Vice President fly to Panama?" - "Because the fighting is over" (from Johnny Carson's The Tonight Show in January 19, 1990).

Haruhiko Yamaguchi has attempted to solve the paradox with the aid of the socalled mention theory that Dan Sperber and Deirdre Wilson had proposed for explaining irony in the early 1980s. According to this theory, ironic utterances are not direct propositions but certain "echoing" references or quotations of some other utterances the speaker wants to ridicule as inappropriate or irrelevant. Yamaguchi's main postulate is that actually, on "narrator's level" maxims are not being violated in jokes, because the speaker delegates the responsibility for the violations "inside the joke" to some character(s) of the narrative. Truly indeed, the bulk of maxim violations seems to happen in the direct speech of joke characters, but they surely can be found in the indirect speech and the so-called narra- 
tive reports as well. Thus Attardo is right in criticising Yamaguchi's view as inconsistent. It is difficult to understand why both Yamaguchi and Attardo criticising him find the problem of narrator's responsibility and guiltiness in particular so important - viz. Attardo (1993: 547-548; 1994: 282-283) in his judgement: "The narrator is always guilty of violation of the CP: either because he/she directly violates one of the maxims or because he/she indirectly does so by not exposing the violation of which he/she is aware." But in itself, rising the question of "the level of responsibility" does have to be important, as it ties the maxim violations with other eternally actual generic issues, like a) the infamous problem of authorship; b) the problem of levels of verbal communication, particularly distinguishing between "primary" ("purely linguistic") and "secondary" (including figurative and humorous) levels and types of text; c) relationship between the familiar and the new in communication, differences in processing information stored in entrenched memory schemas and innovative information that needs cognitive efforts. For example, the structure of responsibility would certainly prove different for the author jokes and anonymous traditional jokes and would depend on the configuration of speaker's roles in the narrating process (either only as a mediator, or an author and teller at the same time).

Nevertheless, attempts to address all responsibility for maxim violations in jokes to one single "level of guiltiness" leave the impression of purely theoretical manipulations - be it Yamaguchi's "Character is guilty", or Attardo's "Narrator is guilty", or shifts to the opposite, impersonal directions, like "The author is guilty" or "Folklore $\sim$ tradition culture is guilty" that are also possible when considering the original "stronger" version of the mention theory which allows also socalled implicit mentioning.

Moreover, it can be asked whether there is a good reason to see a paradox here at all. If the concepts are handled in a slightly extended way, one could get an impression that jokes are totally congested with maxim violations, so that at least one maxim is not violated in each joke, but virtually all maxims are violated in virtually any joke. As jokes convey fictitious events, dialogues, utterances, they already thereby violate the Maxim of Quality. Each punchlined joke would violate the Maxim of Quantity as it fails to convey a part of necessary information. Each nonsense joke (or, in fact, any incongruity) ignores the rule of text's thematic coherence and thus also the Maxim of Relation; each pun (or, in fact, the "bisociativity" of jokes itself) violates its submaxim "Avoid ambiguity". Consequently, it seems reasonable simply to radically enlarge the extent of the concept of communication, calmly to admit plurality of different levels and types of human communication and predictably numerous contradictions between them. Grice's (1991 [1989]) own view on cooperativity and maxims is actually very loose and flexible - see, e.g. his formulation of the Cooperative Principle: "Make your conversational contribution such as is required, at the stage at which it occurs, by the accepted purpose or direction of the talk exchange in which you are engaged" (p. 26). He does not compel to restrict the ambit of maxims to the level of some "apoetic" everyday conversation. He admits that the eventual number of maxims needs not to be limited to four, identification of them may be questionable, maxims differ in their weight, following different maxims simultaneously may prove 
impossible, some violations (e.g. flouting) look more deliberate than others (e.g. violating), etc. Grice (p. 33) explicitly includes under maxim violations also quasitautologies, like Boys are boys, Women are women, War is war, irony, metaphor, hyperbole and ellipse.

Attardo's attitude towards Raskin's “non-bona-fide" conception is notably critical in his earlier work on pragmatics of jokes (1993: 545-546, 551) and notably mild and consensual in a later one (1994: 286-288). In 1993, Raskin's theory is seen as weak mostly in two respects: a) it allegedly severs any connections of "non-bonafide" communication with primary "bona-fide" communication; b) Raskin overestimates the role of specific "contextual clues" that prime the transition from usual to humorous type of communication: in the so-called dead pan jokes, for example, such primers are being deliberately suppressed and avoided. I do not know anything about the nature of personal communication between Raskin and Attardo at the beginning of the 1990s. Anyway, in 1992 Raskin had issued two papers in series Proceedings of the Deseret Language and Linguistic Society, where he proposed his renewed and crystallised views on the same topics but which have remained inaccessible to me. Therefore I can cite here only Attardo's (1994: 286287) ultimately positive comment on these works:

In practice, it establishes a hierarchy of CPs [= Cooperative Principles]. The lowest common denominator is the original CP, but then a humor-CP is introduced which can accom[m]odate the original CP, but can also allow violations of the CP as long as they are eventually redeemed by an ulterior humorous intent. Other CPs seem to exist, as well as a "meta-CP" which regulates violations of the $C P$.

Now Attardo (1994: 287) has also found that already in his earlier book (1985: 104) Raskin had "hypothesized an "extended form of bona fide communication" incorporating humor (and governed by both Grice's maxims and the "humor maxims")", and continues Raskin's contemplations with his own daring and determined hypotheses on bivalent indiscernibility of the sincere and humorous use of language:

It seems also that a radical dichotomy between "serious" BF [= bona-fide] use of language and "humorous" NBF [= non-bona-fide] cannot be maintained in reality. Grice's hypothesized speaker, totally committed to the truth and relevance of his / her utterances, is a useful abstraction, but should be considered only as such. In reality, speakers engaged in everyday communication use humorous remarks that hearers decode, interpret as such, and use along with other information to build their vision of the communicative context. (ibidem).

So a theoretically promising launching pad is created for further new insights in pragmatics of jokes. True, for the time being, Attardo has not yet used it for a new breakthrough. 


\section{ATTARDO: THE SETUP-INCONGRUITY-RESOLUTION MODEL OF HUMOUR (SIR)}

I can only vaguely imagine (perhaps totally missing the point) the eventual theoretical impulses that motivated Attardo to write his article "The semantic foundations of cognitive theory of humor" (1997):

1. By the middle of the $1990 \mathrm{~s}$, the cognitive paradigm had become predominant in linguistics, psychology, anthropology and elsewhere, but the new cognitive ideas and keynotes were perhaps inadequately reflected in the previous GTVH and IDM models developed by Raskin and Attardo.

2. As to their authorship and mentality, the GTVH and IDM were closely related "half-brothers", though very diverse in their form and functions. Both of them were based on the principle of linearity, but in either the linearly configured units were widely different - linearly ordered "knowledge resources" in the GTVH, and linearly ordered real lexical elements of the joke text in IDM. Scripts isotopies were essential constituents of both thereat, however, IDM did not specify the "ontological" status of their oppositeness incongruity, but aimed to depict the linear course of understanding a joke.

3. In IDM, the semantic common part of scripts was defined as "connector" only in terms of verbal jokes (practically, puns), but was left conceptually indefinite for the referential jokes.

4. In both models, Aubouin's "justification" and Ziv's "local logic" fly around like free souls, imploring for further specification.

5. LM component of the GTVH, the notorious "logical mechanism" had been Attardo's enfant terrible since its birth and behaved inadequately in Ruch's test as well.

6. Already in the 1970 s, psychologists had worked out various conceptions of humour which were essentially very congenial to incongruity theories - e.g. the socalled incongruity-resolution model (IR) by Jerry M. Suls (1972). In psychological theories of humour and figurative speech the terms like salience, expectation, access(ibility), etc. originating from Eleanor Rosch's famous theory of prototypes were also largely in use.

After a brief detour to the history of incongruity theories (p. 396-398), Attardo inspects closely the notion of "local antonymy" in Raskin's SSTH model and finds it circular, because it includes a reference to the humorous purposes of the discourse (p. 399). Neither can local antonymy be reduced to simple logical negation, since Raskin's term opposition implies something stronger and more specific ( $\mathrm{p}$. 400). When looking for better alternatives (pp. 401ff.), Attardo finds the key to specifying the concept of opposition in the idea of accessibility proposed by Paul De Palma and E. Judith Weiner and based on more general notions of prototypicality, salience, and parallelism. The units stored in our memory, including scripts, submeanings of polysemous words, etc., are not equal in their accessi- 
bility $\sim$ retrievability salience. In our long-term memory context-free as well as context-bound information is kept. The former is shared by the majority of speakers and is much easier to access, while the latter is brought to the working memory only if the context is relevant. Attardo has also found inspiration in Rachel Giora's ideas of Graded Salience Hypothesis, Relevance Requirement, Graded Informativeness Requirement, Marked Informativeness Requirement, etc. According to Giora, a text has to be relevant, starting with less informative material and proceeding, step by step, to more informative one. In the joke, on the contrary, the jump from the unmarked to the marked information must be sudden, otherwise the punchline effect may be destroyed. So, the first script of the joke is based on a neutral context and is thus easily accessible, whereas the second script depends strongly on the context and is thus much harder to access. Once the first script is activated, the inertia of parallelism forces us to continue the interpretation in the same spirit, until it becomes impossible, since we encounter the disjunctor.

After this theoretical prelude, Attardo arrives at the conclusion that "opposition" in jokes can be redefined from being a certain relationship between scripts simply to the "presence of a second script which is both low in accessibility and high in informativeness" (p. 402; spacing by the author of this paper. - A. K.), and declares soon below: "...I am going to argue precisely that SO [= script opposition] and incongruity are different conceptualizations of the same phenomenon" ( $p$. 403). Considering that the traditional term "contradiction", Koestler's "clash of bisociated contexts", Raskin's "script opposition" or others are, in any case, so far understood intuitively as different manifestations of the same "emic" idea of incongruity, it is hard for me to decide how innovative the cited statements are. The ideas of accessibility, salience, informativeness, markedness, etc. as context-dependent lead Attardo to problematise Raskin's, as it were, "the hardwired list of SOs" and to propose that "the list of SOs can be eliminated because the theory would now generate its own SO from scratch each time, based on the accessibility values calculated in the text" (pp. 404-405). (It is worth noting here, as an interesting parallel, that at about the same time in cognitive theory of metaphor the term "schema" was (actually) replaced with the term "mental space" as allegedly more flexible and online-oriented.)

Attardo's next concern is to reconceptualize the hitherto vague and problematic concept of logical mechanism (LM). After references to Aubouin's "justification" and Ziv's "local logic" typical of him, Attardo admits that the LMs described for the GTVH model "consisted essentially in a list of examples of mechanisms: figure-ground reversal, faulty logic, chiasmus, (false) analogy, false priming (in other words, garden path), and mere juxtaposition" (p. 408) and failed in Ruch's test experiment. The way Attardo offers to locate the LM is really astonishing. As the psychological models by Suls and others included the phase of resolution without any counterpart in Attardo's own previous models and, on the other hand, his LMs had long looked for their place under the sun, he finds "that the two are basically different conceptualizations of the same phenomenon. In other words, the LM of a joke is the resolution of the SO (incongruity)" (p. 409; italics by Attardo), and reasserts a paragraph further: "It should be noted that I am claiming that 
the LM is the resolution itself, not just an enabling mechanism thereof" (ibidem). The notion of juxtaposition is thought to be central in the structure of LMs and to serve as their "common denominator". However, there is a serious reason to question the identity of the notions of LM and resolution, considering the real "online process" of joking. Regardless of the really scanty number of empirical examples, LMs seem ready-made "traps of faulty logic" set up for the hearer, put in the minds and mouths of the joke characters and/or invoked via various 'gardenpath' or other techniques of false priming. Resolution, on the grounds of everything said about it, involves the real mental operations the receiver's mind performs to cope with these traps.

Finally, SO being equalised with incongruity and LM with resolution, Attardo gives the name "setup" to the initial part of the joke text preceding them: "I propose to consider the setup phase as corresponding to the SSTH's "overlap of scripts"' (p. 413). But as the overlap of scripts can be identified only after the outcome of the second script, it can be said that "the setup phase is just the instantiation of the first script" (ibidem). Attardo does not mention explicitly that one of the motives for inserting the setup component might have been the absence of any termed counterpart of the element of disjunctor for the rest of the jokes, except puns.

\section{TAXONOMY OF LOGICAL MECHANISMS. ATTEMPT TO APPLY SET AND GRAPH THEORIES}

Attardo has an immutable faith in formalized methods of studying humour and has bequeathed it to some of his students. Two of them are Christian F. Hempelmann and Sara Di Maio. Di Maio defended her PhD thesis "A Structured Resource for Computational Humor" in 2000 at the University of Siena, Hempelmann's thesis was defended at the Purdue University in 2003 and concerned the automatic generation of paranomastic puns.

In their joint work "Script oppositions and logical mechanisms: Modeling incongruities and their resolutions" (2002), Attardo, Hempelmann and Di Maio aim to give a survey of "all known logical mechanisms" and make an attempt to give a closer taxonomy of them. As for additional sources, they use their own data bases (fully unknown to me) and the analysis of Gary Larson's Far Side Cartoons by John C. Paulillo (1998: 270ff.). They compile a list of all so far fixed LMs (27 units altogether), find them quite different as to their degree of generality, and make two taxonomic summaries of them - one on the grounds of the syntagmatic relationships of LMs (p. 18), another on the grounds of ways of reasoning in them (correct, faulty, "meta-") (p. 19). Both generalizing taxonomies have a hierarchical, tree-shaped structure. One can predict the emerging two bundles of problems regarding their practical applicability.

1. Most of the types of LMs are illustrated with only one or two text examples. I do not know, unfortunately, how strong was the full empirical basis for the classification of LMs, how carefully it was tested and whether or not the authors had 
difficulties in relating particular texts with particular categories. Anyhow, the actual multitude of existing joke texts is so great and sometimes so continuous that, very probably, the division of any relatively large and typologically diverse set of texts into 27 discrete and focal boxes of LMs (see p. 18) should not take place without hesitation between many alternative choices and the arbitrariness of many decisions. Further, no additional comments specifying any indefinitely comprehensive "headline" of this or that LM are given. In Krikmann (2004) I have improvised some situations exemplifying possibilities to fulfil the categories of "vicious circle" and "coincidence" with drastically heterogeneous jokes.

2. As just said, the terms used for identifying the lower level categories of LMs are (let alone their relationships with joke texts themselves) also per se impressionistic enough to fall into various synonymous, hypo-/hyperonymic, causal, etc. relationships with each other and, in addition, tend to coincide with terms that are in use in the theory of figurative language or elsewhere. So, "analogy" (p. 10) and "parallelism" (p. 12) seem dangerously synonymous for the LM-categorisation of joke texts in practice. For example, LM is identified as "analogy" in the following joke:

Mr. Smith got himself a new secretary. She was young, sweet, and very polite. One day while taking dictation, she noticed his fly was open. When leaving the room, she said: "Mr. Smith, your barrack's door is open." He did not understand her remark. But, later on, he happened to look down and saw his zipper was open. He decided to have some fun with his secretary. Calling her in, he asked: "By the way, Miss Jones, when you saw my barrack's door was open this morning, did you also notice a soldier standing at attention?" The secretary, who was quite witty, replied, "Why, no sir. All I saw was a little disabled veteran sitting on two duffel bags."(Ibidem: 10).

Typologically, this joke is a close relative with the well-known anecdote where Churchill answers Roosevelt's comment about his fly being open with a proverblike allegory: "An old eagle doesn't fall out of the nest" "A dead hawk doesn't fly out of its nest", or the like. But in the former, the problem is in inventing the witty repartee, whereas in the latter - in deciphering the actual meaning of Churchill's allegory by Stalin's secret service. Are they then equal or different as to their LMs?

For "Kommen Sie aus Deutschland oder aus Überzeugung?" (p. 12) the LM is qualified as "parallelism" - though, "parallelism" with its enormous field of meaning is evidently too loose to convey what exactly was meant, and in rhetoric the term "zeugma" is used for instances like this.

LM for the Freudian "A wife is like an umbrella. Sooner or later one takes a cab" (p. 13) is fully justifiably termed as "proportion". But no notice is made about the glorious pedigree of A:B :: C:D structures in rhetoric, from Aristotle to Mark Turner's famous XYZ structures (see e.g. Turner 1987; 1991: 183-215; 1996: 104-108; 1998: 52-55; Fauconnier \& Turner 2002: 140-168). Among XYZ structures there are certainly many serious proverbial items, but the XYZ-shaped ending part of 
the aphorism borrowed from Clifton Fadiman "[A cheese may disappoint. It may be dull, it may be naive, it may be oversophisticated. Yet it remains] cheese, milk's leap toward immortality" (see Turner 1991: 203, 252) undoubtedly belongs in humour.

"Missing link", "consequence", "field restriction", "exaggeration" and others seem equally too gray-scaled for practical purposes.

Attardo et al. (2002) is evidently addressed to the broad circle of humour scholars and other readers without any special knowledge in set or graph theories. Therefore the second part of the article introduces some general elements of the theories mentioned (p. 22 and 31-34, respectively). Further, the "translations" of SO and LM components of some jokes examples to set and graph theory formalism are presented, as well as graphic interpretations of some joke texts in the form of Venn's diagrams or otherwise. I do not know the current state of research in computer modelling of jokes and therefore cannot evaluate the efficiency of models created so far. Intuitively, also considering the achievements in modelling usual language, success ought to be relatively moderate. Neither is the present state of humour theoretical constructions by Raskin, Attardo and others adequate enough for producing any substantial help, e.g. providing at least a minimal number of elements of a "vocabulary" or "alphabet" for building such models. So the elements of set and graph theory applications in Attardo et al. 2002 also remain simply nice "things in themselves", they are not used for any further calculations, or for anything else. Actually, there is also no need to apply graph theory to get schemas depicting certain structural aspects of joke texts, like those on pp. 31, 35, 37 , and 38. Besides, the alleged use of the graph theory does not protect them from errors sprung up already in the "preformal" stage of analysis. In Krikmann (2004: 113-115) the fate of an error of this type in the script structure of Raskin's famous "bronchial patient's" joke is looked in more detail.

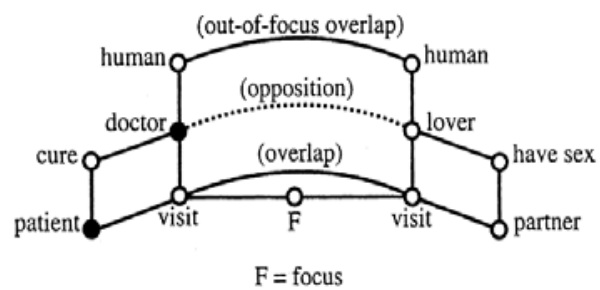

The graph above not only retains but removes ambiguity in a wrong direction of the above-mentioned ambiguity caused from defining the involved script opposition as DOCTOR : LOVER (not PATIENT : LOVER). The ambiguity is not a problem until we understand this as conditional labelling of certain events or situations (visiting the doctor vs. visiting the lover), not as different roles the whispering man plays in either script. But in the schema above, just the latter, i.e. wrong graphical solution is chosen, despite of the added correct verbal explanation of 
the schema: “...both the patient visiting the doctor and the lover visiting his wife [---] are agents of the actions they respectively perform" (p. 35; spacing by the author of this paper. - A. K.).

Outside the set and graph theoretical simulations, the verbal analyses of many joke examples are, in any sense content-rich, interesting and convincing, especially these of the joke about the raped nun (p. 30-31; cf. also above).

\section{THE “ANTI-FESTSCHRIFT” FOR RASKIN}

On April 17, 2004 Victor Raskin celebrated his $60^{\text {th }}$ birthday and Attardo, now the chief editor of the journal HUMOR, proposed to dedicate an issue of the journal (vol.17, no. 4) to Raskin's diamond jubilee. Raskin had been pleased and enthusiastic about the idea, but had imposed a surprising precondition: only these authors should be invited to contribute who would be willing to criticize his theoretical views or work in general. This restriction compelled many renowned humour scholars to abandon the idea and refuse, with deep regret, from their contribution.

In Krikmann (2004: 117-134) one can find an extensive survey of papers included in the "anti-Festschrift". Here I will present only a brief list of the main postulates proposed by the contributors.

1. All attempts of researching and classifying the phenomena of the so-called logical mechanisms of jokes are fruitless; the LM component must be totally removed from the model, since the aim of the theories should be to generate novel viewpoints and to make testable prognoses, not to compose detailed taxonomies (Davies 2004: 380). The LM component is superfluous in the model of humour; instead, the model could include an account of non-prototypical uses of language accompanied by humorous effects (Brône \& Feyaerts 2004: 364).

2. Models elaborated by Raskin and Attardo for the analysis of jokes are not extendable to other kinds of humour, e.g. to longer humorous texts with a more compound structure (Triezenberg 2004; Morreall 2004: 400; cf. Attardo 1998 and 2001); to various cases of non-verbal humour where the participants are not divided into speakers and listeners and two-sided interaction is required (Norrick 2004); to primitive forms of ancient humour (Morreall 2004).

3. Distinguishing bona-fide / non-bona-fide types of communication, as well as incongruity and resolution, are not sufficient conditions for inducing humorous effects; the same conditions can be satisfied also in science fiction, detective stories, thrillers, etc. (Morreall 2004; Veale 2004: 424).

4. A humorous text may contain multiple incongruities embracing more than one pair of oppositions, or the script collision may involve more than one plane of meaning (Brock 2004). 
5. Tony Veale (2004) proposes an intriguing original alternative conception. Humour comes into being not because the joke, due to its structural specificity, forces the humorous experience out of the hearer (as Raskin's and Attardo's theories imply), but because the recipient as a social being is already attuned and welldisposed towards humour in advance, adjusted to seek humour wherever it is possible. Thus the humorous experience is a two-sided, cooperative social act. Therefore

a humor theory must not look for incongruities, but provide a social explanation for why we enjoy insulting others and why a feeling of social intimacy can arise when this insult is licensed by the cooperative principle of joke-telling.

[---] What is needed is not a logical mechanism as such, or a logic of oppositions, but a social logic that allows a theory to ground the interpretation in the specific concerns and prejudices of the listener as a social agent. (Ibidem: 424-425).

And further:

Our social conditioning means it is gratifying to see narratives where pomposity is deflated, excessive authority is thwarted, modesty is rewarded and arrogance is punished. It should not be surprising then to see a listener choose, when given the freedom, an interpretation with the most satisfying trajectory. Office jokes that poke fun at a dictatorial boss or a hopelessly inept colleague work best when we share the scorn of the speaker and thus jump directly to the most derisive interpretation. (Ibidem: 425-426).

Consequently, the humour theory should sooner shift its present focus of interest from SOs and LMs to the "social logic" of jokes and recognize that other theories of humour, including Freudian release theories, are not lacking their kernel of truth either.

6. The contribution by cognitive linguists Kurt Feyaerts and Geert Brône (2004) is congenial and partly overlaps with their previous extended paper (2003) on the same topic. Their basic message is that the script-based models of humour and the working tools of cognitive linguistics have much in common. The former have not yet exhausted the entire arsenal of possible devices elaborated in the latter, and the latter, in turn, have shown too little interest in humour as a topic of research. Feyaerts and Brône are also stressing similarity of humour with phenomena of figurative language (metaphor, metonymy). The bulk of the both works by Feyaerts and Brône is dedicated to the analysis of some German phraseologisms that belong among the so-called verbal insults and represent a certain kind of metonymic hyperbolas. The authors hypothesize that the processing difficulty of figurative phrases can be measured by counting the causal steps detaching the metonymic manifestation of them from the target concept they denote. To their mind, Raskin and Attardo overemphasise the uniqueness of humour "beside" or 
"above" the language, whereas many humorous effects are actually explainable by means of prototypicality, salience and markedness and thus need not depart from the linguistic level. Nevertheless, the works by Feyaerts and Brône sooner resemble an analysis of metonymy than that of humour. It remains unclear whether the metonymical phrases with a more refined structure must contain, at the same time, more humour, or are they simply harder to process.

\section{SUMMARY}

My final conclusion of this brief survey of contemporary linguistic theories of humour tends to be agnostic. It is hard if not impossible to find criteria to evaluate the "objective" state of development of the theories of the humanities: they can be equally regarded as being still in their incipiency, or as enjoying their heyday, or as approaching their end.

\section{Comment}

The article is related to the Estonian Science Foundation grant ETF 6759.

\section{References}

Apte, Mahadev 1985. Humor and Laughter: An Anthropological Approach. Ithaca \& London: Cornell University Press.

Attardo, Salvatore 1988. Trends in European humor research: towards a text model. HUMOR: International Journal of Humor Research, 1 (4), pp. 349-369.

Attardo, Salvatore 1993. Violation of conversational maxims and cooperation: The case of jokes. Journal of Pragmatics, 19 (6), pp. 537-558.

Attardo, Salvatore 1994. Linguistic Theories of Humor. Berlin-New York: Mouton de Gruyter.

Attardo, Salvatore 1997. The semantic foundations of cognitive theories of humor. HUMOR: International Journal of Humor Research, 10 (4), pp. 395-420.

Attardo, Salvatore 1998. The analysis of humorous narratives. HUMOR: International Journal of Humor Research, 11 (3), pp. 231-260.

Attardo, Salvatore 2001. Humorous Texts: A Semantic and Pragmatic Analysis. BerlinNew York: Mouton de Gruyter.

Attardo, Salvatore \& Raskin, Victor 1991. Script theory revis(it)ed: joke similarity and joke representation model. HUMOR: International Journal of Humor Research, 4 (3/ 4), pp. 293-347.

Attardo et al. 1994 = Attardo, Salvatore, Attardo, Donalee Hughes, Baltes, Paul \& Petray, Marnie Jo. The linear organization of jokes: analysis of two thousand texts. HUMOR: International Journal of Humor Research, 7 (1), pp. 27-54.

Attardo et al. 2002 = Attardo, Salvatore, Hempelmann, Christian F. \& Di Maio, Sara. Script oppositions and logical mechanisms: Modeling incongruities and their resolutions. HUMOR: International Journal of Humor Research, 15 (1), pp. 3-46. 
Berger, Peter L. 1997. Redeeming Laughter: The Comic Dimension of Human Experience. New York-Berlin: Walter de Gruyter.

Brock, Alexander 2004. Analyzing scripts in humorous communication. HUMOR: International Journal of Humor Research, 17 (4), pp. 353-360.

Brône, Geert \& Feyaerts, Kurt 2003. The cognitive linguistics of incongruity resolution: Marked reference-point structures in humor. [8th International Cognitive Linguistics Conference: July 20-25, 2003, University of La Rioja, Spain. Theme session: CognitiveLinguistic Approaches to Humour]. http://wwwling.arts.kuleuven.ac.be/iclc/Papers/ BroneFeyaerts.pdf

Brône, Geert \& Feyaerts, Kurt 2004. Assessing the SSTH and GTVH: A view from cognitive linguistics. HUMOR: International Journal of Humor Research, 17 (4), pp. 361372.

Coulson, Seana 1997. Semantic Leaps: The role of frame-shifting and conceptual blending in meaning construction. PhD Thesis. University of California, San Diego.

Davies, Christie 1990. Ethnic Humor Around the World: A Comparative Analysis. Bloomington \& Indianapolis: Indiana University Press.

Davies, Christie 1998. Jokes and their Relations to Society. Berlin \& New York: Mouton de Gruyter.

Davies, Christie 2004. Victor Raskin on jokes. HUMOR: International Journal of Humor Research, 17 (4), pp. 373-380.

De Palma, Paul ja Weiner, E. Judith 1992. Riddles: Accessibility and Knowledge Representation. [Proc. of COLING-92, Nantes, Aug. 23-28, 1992]. http://acl.ldc.upenn.edu/ C/C92/C92-4176.pdf

Fauconnier, Gilles \& Turner, Mark 2002. The Way We Think: Conceptual Blending and the Mind's Hidden Complexities. New York: Basic Books.

Fry, William F. 2002. Humor and the brain: A selective review. HUMOR: International Journal of Humor Research, 15 (3), pp. 305-333.

Grice, Paul 1991 [1989]. Studies in the Way of Words. Cambridge, Mass. \& London, UK: Harvard University Press.

Gruner, Charles R. 2000 [1997]. The Game of Humor: A Comprehensive Theory of Why We Laugh. New Brunswick-London: Transaction Publishers.

Hempelmann, Christian F. 2003. Paronomasic Puns: Target Recoverability Towards Automatic Generation. PhD thesis. Purdue University, Indiana.

Johnson, Ragnar 1976. Two Realms and a Joke: Bisociation Theories of Joking. Semiotica, 16 (3), pp. 195-221.

Keith-Spiegel, Patricia 1972. Early Conceptions of Humor: Varieties and Issues. Jeffrey H. Goldstein, Paul E. McGhee (eds.). The Psychology of Humor: Theoretical Perspectives and Empirical Issues. New York-London: Academic Press, pp. 3-39.

Knuuttila, Seppo 1992. Kansanhuumorin mieli: Kaskut maailmankuvan aineksena. Helsinki: SKS.

Koestler, Arthur 1964. The Act of Creation. London: Hutchinson \& Co.

Krikmann, Arvo 2004. Koestler, Raskin, Attardo ja teised: Lingvistiliste huumoriteooriate uuemaist arenguist. Reetor, 4. Tartu: EKM, EKFK.

Latta, Robert L. 1999. The Basic Humor Process: A Cognitive-Shift Theory and the Case against Incongruity. Berlin \& New York: Mouton de Gruyter [1998].

McGhee, Paul E. 1979. Humor: Its Origin and Development. San Francisco: W. H. Freeman and Company.

Milner, George Bertram 1972. Homo Ridens: Toward a Semiotic Theory of Humour and Laughter. Semiotica, 5 (1), pp. 1-30.

Morreall, John (ed.) 1987. The Philosophy of Laughter and Humor. New York: State University of New York Press. 
Morreall, John 2004. Verbal humor without switching scripts and without non-bonafide communication. HUMOR: International Journal of Humor Research, 17 (4), pp. 393400.

Mulkay, Michael 1988. On Humour: Its Nature and Its Place in Modern Society. Cambridge \& Oxford \& New York: Polity Press.

Norrick, Neal R. 1993. Conversational Joking: Humor in Everyday Talk. Bloomington \& Indianapolis: Indiana University Press.

Norrick, Neal R. 2004. Non-verbal humor and joke performance. HUMOR: International Journal of Humor Research, 17 (4), pp. 401-409.

Oring, Elliott 1992. Jokes and Their Relations. Lexington: The University Press of Kentucky.

Paulillo, John C. 1998. Gary Larson's Far Side: Nonsense? Nonsense! HUMOR: International Journal of Humor Research, 11 (3), pp. 261-290.

Provine, Robert R. 2000. Laughter: A Scientific Investigation. New York: Viking.

Raju, Alison 1991. Decoding the Comic. Gillian Bennett (ed.). Spoken in Jest. Sheffield: Sheffield Academic Press, pp. 69-82.

Raskin, Victor 1985. Semantic Mechanisms of Humor. Dordrecht \& Boston \& Lancaster:

D. Reidel Publishing Company.

Raskin, Victor \& Attardo, Salvatore 1994. Non-literalness and non-bona-fide in language. Pragmatics and Cognition, 2 (1), pp. 31-69.

Ritchie, Graeme 2001. Current Directions in Computational Humour. Artificial Intelligence Review, 16 (2), pp. 119-135.

Ruch et al. 1993 = Ruch, Willibald, Attardo, Salvatore ja Raskin, Victor. Toward an empirical verification of the General Theory of Verbal Humor. HUMOR: International Journal of Humor Research, 6 (2), pp. 123-136.

Russell, Roy E. 2000. Humor's close relatives. HUMOR: International Journal of Humor Research, 13 (2), pp. 219-233.

Suls, Jerry M. 1972. A Two-Stage Model for the Appreciation of Jokes and Cartoons: An Information-Processing Analysis. Jeffrey H. Goldstein \& Paul E. McGhee (eds.). The Psychology of Humor: Theoretical Perspectives and Empirical Issues. New York-London: Academic Press, pp. 81-100.

Triezenberg, Katrina 2004. Humor enhancers in the study of humorous literature. HUMOR: International Journal of Humor Research, 17 (4), pp. 411-418.

Turner, Mark 1987. Death is the Mother of Beauty: Mind, Metaphor, Criticism. Chicago: Chicago University Press. http://www.wam.umd.edu/ mturn/WWW/DMB.WWW/ dmbfront.html

Turner, Mark 1991. Reading Minds: The Study of English in the Age of Cognitive Science. Princeton, N.J.: Princeton University Press.

Turner, Mark 1996. The Literary Mind:The Origins of Thought and Language. OxfordNew York: Oxford University Press.

Turner, Mark 1998. Figure. Albert N. Katz, Cristina Cacciari, Raymond W. Gibbs Jr., Mark Turner (eds.). Figurative Language and Thought. Oxford \& New York: Oxford University Press, pp. 44-87.

Veale, Tony 2004. Incongruity in humor: Root cause or epiphenomenon? HUMOR: International Journal of Humor Research, 17 (4), pp. 419-428.

Weeks, Mark C. 2002. Laughter, desire, and time. HUMOR: International Journal of Humor Research, 15 (4), pp. 383-400. 
